\title{
The spatial domain of wildfire risk and response in the wildland urban interface in Sydney, Australia
}

\author{
O. F. Price and R. A. Bradstock \\ Centre for Environmental Risk Management of Bushfires, Institute for Conservation Biology and Environmental \\ Management, University of Wollongong, NSW 2522, Australia
}

Correspondence to: O. F. Price (oprice@uow.edu.au)

Received: 18 June 2013 - Published in Nat. Hazards Earth Syst. Sci. Discuss.: 6 September 2013

Revised: 17 November 2013 - Accepted: 19 November 2013 - Published: 23 December 2013

\begin{abstract}
In order to quantify the risks from fire at the wildland urban interface (WUI), it is important to understand where fires occur and their likelihood of spreading to the WUI. For each of the 999 fires in the Sydney region we calculated the distance between the ignition and the WUI, the fire's weather and wind direction and whether it spread to the WUI. The likelihood of burning the WUI was analysed using binomial regression. Weather and distance interacted such that under mild weather conditions, the model predicted only a $5 \%$ chance that a fire starting $>2.5 \mathrm{~km}$ from the interface would reach it, whereas when the conditions are extreme the predicted chance remained above $30 \%$ even at distances $>10 \mathrm{~km}$. Fires were more likely to spread to the WUI if the wind was from the west and in the western side of the region. We examined whether the management responses to wildfires are commensurate with risk by comparing the distribution of distance to the WUI of wildfires with roads and prescribed fires. Prescribed fires and roads were concentrated nearer to the WUI than wildfires as a whole, but further away than wildfires that burnt the WUI under extreme weather conditions (high risk fires). Overall, $79 \%$ of these high risk fires started within $2 \mathrm{~km}$ of the WUI, so there is some argument for concentrating more management effort near the WUI. By substituting climate change scenario weather into the statistical model, we predicted a small increase in the risk of fires spreading to the WUI, but the increase will be greater under extreme weather. This approach has a variety of uses, including mapping fire risk and improving the ability to match fire management responses to the threat from each fire. They also provide a baseline from which a cost-benefit analysis of complementary fire management strategies can be conducted.
\end{abstract}

\section{Introduction}

Knowledge for estimating and mitigating risk from wildfires is most critical at the wildland urban interface (WUI): the boundary between flammable vegetation and the houses and other assets in the urban land (Safford et al., 2009; Mell et al., 2010). As urban populations expand, so do the number of houses in the WUI in Australia (Hughes and Mercer, 2009) and in the USA (Schoennagel et al., 2009), and house losses increase accordingly (Schoennagel et al., 2009). The probability of loss (consequential risk) is a conditional function of ignition, spread and the vulnerability of urban environments and structures (Bradstock and Gill, 2001). Much of the emphasis on risk research is on the latter (Bhandary and Muller, 2009; Blanchi et al., 2010). The risk consequences of ignition and spread have a strong spatial component that awaits more formal scrutiny (i.e. the chance of a fire reaching the WUI given the location of its ignition). This is important because management options for the treatment of fuel and co-location of measures for facilitating suppression (i.e. road, track networks) need to be carefully positioned in landscapes in order to be effective.

Choices about where to position these management activities are made heuristically. In many jurisdictions, management is based on a bet hedging exercise, with varying mixtures of treatments and access focussed at the WUI and in the wider landscape. In some jurisdictions, these are mandated by planned zoning systems. An understanding of the likelihood that any ignition will result in a fire that reaches the WUI, based on its location, distance and environmental context (e.g. weather at the time) from the WUI, will yield insight into the likely efficacy of current and future 
configurations of management actions (prevention and suppression). For example, there is little benefit in treating fuels $10 \mathrm{~km}$ away from the WUI if most of the wildfires ignite only $5 \mathrm{~km}$ away. This insight will also be important for planning responses to changing human development patterns and future fire weather. In addition, such an understanding will inform residents of the risks they face (Stockmann et al., 2010) and provides an essential source of information for decision analysis of optimal management strategies.

This study therefore examined the following.

1. The relationship between distance and the chance that an ignition will result in a fire reaching the WUI, and the way that weather conditions influence this chance. This leads to a spatially explicit domain of "likelihood", which is largely unquantified in many parts of the world.

2. The degree to which the distribution of current road and fuel treatment networks conform with spatial gradients of likelihood, as defined above.

3. The degree of change in likelihood of fire spreading to the WUI under climatic change.

Sydney in south-eastern Australia was chosen as the study area. Sydney has an extensive WUI and highly flammable forest vegetation abutting the WUI in many places. As a result, houses have been destroyed by fire in 12 of the past 43 fire seasons (1970-2013) (Ellis et al., 2004; Rural Fire Service, unpublished data).

The likelihood that a fire will reach the interface is a consequence of two factors: the likelihood that an ignition will occur in the landscape and the likelihood that it will spread to the interface. Fire history maps are invaluable for quantifying both of these factors and a probabilistic model of the chance of spread to the interface can be derived from past fires. Specifically, if the ignition points and final perimeters of fires are known, then it is possible to determine which fires reached the interface and model the probability as a function of distance between the interface and the ignition and other potential drivers. It is this aspect that we focus on in this study: the likelihood that a fire will spread to the interface. We were particularly interested in the interaction between two important drivers of risk: the distance of the ignition from the WUI and weather. There are other drivers of the risk of spread, in particular the load and distribution of fuels, but their inclusion would involve complex spatial integration of data more suitable to different analyses, which are the subject of our current research.

This study is the first to quantify from empirical data, the likelihood that fires originating outside will spread to the WUI. It is also the first to examine the effect of individual fires on the WUI using a large sample. Previous studies of fire risk in the WUI have either examined the effects of a single fire on house loss (Bhandary and Muller, 2009; Brillinger et al., 2009); used measures of fire regime (such as the number of fires over a period (Haight et al., 2004)); simulated fires (Stockmann et al., 2010; Bar Massada et al., 2009) or have abstracted risk to some extent (such as measuring how intense a fire would be if it occurred (Bradstock et al., 1998)).

\section{Methods}

\subsection{Study area}

Greater Sydney is a city of 4.7 million people (Australian Bureau of Statistics figures, 2012), lying in a highly developed coastal lowland plain (the Cumberland Plain) surrounded by dissected sandstone tablelands (Fig. 1). The native vegetation in the tablelands is largely intact and is dominated by a diverse dry and wet sclerophyll eucalypt forest, with a total area of approximately $20000 \mathrm{~km}^{2}$. Rainforests, wetlands, heathlands and grasslands represent only minor components of the vegetation $(<2 \%$ each, Tozer et al., 2006). Urban development abuts the forest around the edge of the city and there are fingers of development into the tablelands. There are also many forested patches within the city, usually associated with steep and rugged drainage lines. The WUI in the Sydney region has a length of approximately $7000 \mathrm{~km}$ (from the data derived in this study). The climate is warm and temperate, and the rainfall total of $1200 \mathrm{~mm}$ is evenly distributed through the year (Bureau of Meteorology data for Sydney Airport). An average of $5 \%$ of the forest is burnt by unplanned fires each year, though up to $20 \%$ can burn in one year, and another $1 \%$ is burnt by prescribed burning (Price and Bradstock, 2011). Houses are lost to unplanned fires in approximately one quarter of years (Ellis et al., 2004).

\subsection{Data}

We used the New South Wales (NSW) Digital Cadastral Database (www.lpi.nsw.gov.au/mapping_and_magery/ spatial_data/cadastral_data, last accessed: July 2007) to define urban areas as those where there were $>2$ properties per ha (using a 1 ha grid size). Then we defined the WUI to be a $500 \mathrm{~m}$ buffer around those urban areas. The total perimeter of the urban area thus defined was $7672 \mathrm{~km}$, or $6303 \mathrm{~km}$ if only urban patches larger than 10 ha are included. The $500 \mathrm{~m}$ buffer corresponds to the Strategic Fire Advantage Zone used in bush fire risk management plans in NSW (Anon, 2008). We used this buffer zone as the interface rather than the actual edge of the urban areas to reduce the possible underestimation of the number of fires that reached the WUI caused by fire suppression, which is usually most active right at the urban edge. We were unable to estimate the proportion of fires that may have been stopped by suppression, due to lack of appropriate information. We refer to this zone as the WUI buffer. Of all fires, $27 \%$ were recorded as starting within the WUI buffer, and these were excluded from the analysis. 


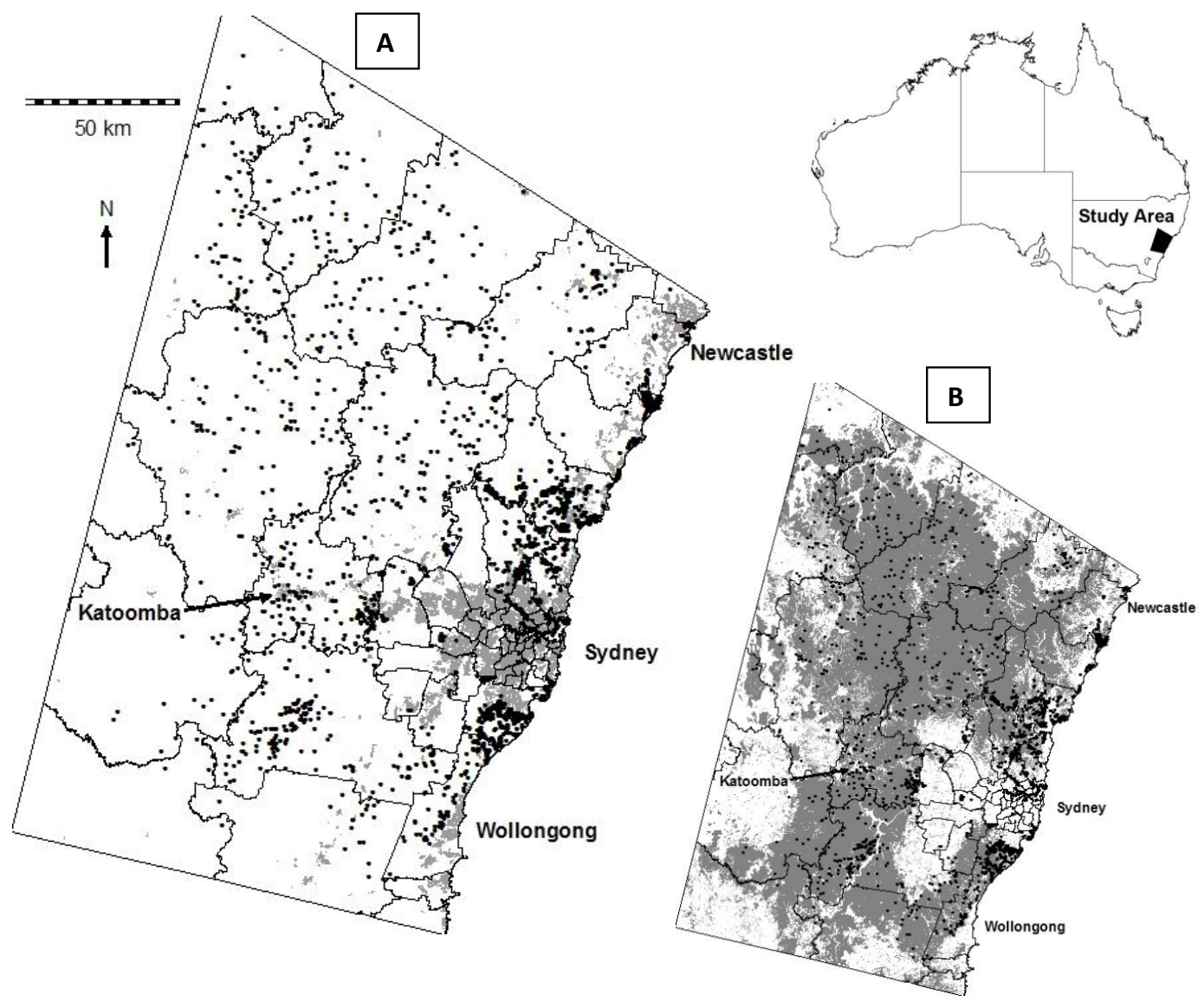

Fig. 1. The study area, showing (A) the ignition points of all fires and the defined urban land (grey shading) and (B) forested vegetation surrounding Sydney (grey shading) (Office of Environment and Heritage, unpublished data 2011).

Several aspects of the geography vary within the study region. Since the main urban centre of Sydney is approximately in the centre of the region, the dominant direction between the interface and the forest varies among the compass sectors. The relative amount of forest compared to other land uses varies and the east has a more coastal influence. To control for the possibility that these differences may alter fire behaviour, we divided the region into four geographic zones (NE, SE, SW and NW) and also included wind direction (N, $\mathrm{S}, \mathrm{E}$ or $\mathrm{W}$ ) in the analysis.

Ignition locations and perimeters of all unplanned fires from the years 1977-2008 were derived from mapped fire history records and incident reports provided by the New South Wales Office of Environment and Heritage (OEH) (unpublished data). Each ignition was assigned to one of five nearest Bureau of Meteorology weather stations: Nullo Mountain, Mount Boyce, Cessnock, Moss Vale and Richmond (mean distance $43 \mathrm{~km}$ ). Then, by cross-referencing with the ignition date, the Forest Fire Danger Index (FFDI) (McArthur, 1967) and the wind-direction at 15:00 LT (local time) were recorded. FFDI reflects both the current weather conditions (via coefficients for daily temperature, humidity and wind speed) and medium term rainfall (via the drought factor coefficient). It is commonly used to measure the risks associated with current fires in Australia, and has been shown to be a good predictor of fire spread and the occurrence of large fires in this region (Price and Bradstock, 2010; Bradstock et al., 2009). The fire danger rating system classifies an FFDI below 5 as "low" and an FFDI between 50 and 75 as "severe". Many of the ignitions had missing attributes due to missing date recordings or gaps in the weather records. There were 2615 fires with known ignition points and 999 cases with sufficient data to analyse. The variables are described in Table 1a.

The distances to the WUI buffer of the centroids of all 3112 prescribed burns during the same period were calculated. Centroids are the geographical centre of a feature, which is the actual centre for a regular polygon such as a square but can be outside a convoluted polygon. They are a good measure of the location of prescribed burns as the median size of patches was 14.0 ha. Thus no part of the patch is likely to be $>200 \mathrm{~m}$ away from the centroid. Distance to the WUI buffer was also calculated for the centroids of all road segments (273000 segments of mean length $236 \mathrm{~m}>$ ). To 
Table 1. Variables and data sets used in the analysis.

(a) Variables used in the generalised linear modelling.

\begin{tabular}{llrr}
\hline Name & Description & Mean & Range \\
\hline $\begin{array}{l}\text { Dependent } \\
\text { Burnt }\end{array}$ & Variable & 0.91 & $0-1$ \\
& Whether or not the fire burnt any part of the WUI buffer & & $10-28933$ \\
Predictor & Variables & Distance from ignition point to the nearest point in the WUI buffer (m) & 5891 \\
Distance & Natural log of distance (m) & 7.75 & $2.30-10.27$ \\
Log(Distance) & Forest Fire Danger Index on the day of ignition & 16.5 \\
FFDI & Wind direction (N, S, E, W) on the day of the ignition & $0.10-86.2$ \\
Wind_dir & Subregions (NW, NE, SE, SW) & 0.72 & $0.00-0.67$ \\
Subregion & Spatially lagged response variable: mean of all other burnt values, & \\
SLRV & weighted by distance to the current ignition & \\
\hline
\end{tabular}

(b) Data sets used for comparing distances to the wildland urban interface buffer.

\begin{tabular}{llrr}
\hline Name & Description & $N$ & Median distance (m) \\
\hline Wildfires & $\begin{array}{l}\text { The known ignitions as used for the generalised linear modelling } \\
\text { analysis }\end{array}$ & 999 & 2523 \\
High Risk Fires & Wildfires ignited on days with FFDI $>25$ and which did spread to & 14 & 406 \\
& the WUI buffer & & \\
Prescribed Fires & All prescribed fires & 3112 & 0 \\
Roads & Road segments & 230000 & 5807 \\
Control & All points in the study area located on a grid of 200 m separation & 1000000 & 000 \\
\hline
\end{tabular}

provide a control set of distances, we calculated the distance to the WUI buffer of all 1 million points in a regular grid with $200 \mathrm{~m}$ separation across the study area. Features with a distribution of distances less than the control set are biased toward the buffer. The cumulative distribution of distances was calculated for each of these features, including wildfire distance and the distance of wildfires that actually burnt the WUI buffer and ignited on days with an FFDI $\geq 50$. The threshold of 50 reflects the findings of Blanchi et al. (2010) that $93 \%$ of house losses in Australia occur on such days. We refer to this set of fires as high risk fires. These five data sets are described in Table $1 b$.

\subsection{Analysis}

The data were explored graphically, and the underlying relationships analysed using binomial regression (McCullagh and Nelder, 1983). We used model selection techniques based on Akaike information criterion (AIC) to derive a best model and supported alternatives for the probability of burning the buffer (Burnham and Anderson, 2002). The response variable was whether the WUI buffer burnt or not (binomial 0 or 1) and there were five predictors: distance, FFDI, wind direction, subregion and a spatially lagged response variable (SLRV, the distance weighted mean of whether all other fires burned the WUI buffer). The SLRV approach is commonly used to control for spatial autocorrelation (Haining, 2003). All the possible model combinations including two-
Table 2. Best model for predicting the probability that a fire will reach the WUI buffer ( $n=999$, percentage of deviance captured $=$ 35.83, AIC $=407.14$, no supported alternatives). FFDI, Forest Fire Danger Index; SLRV, spatially lagged response variable (to control for spatial autocorrelation).

\begin{tabular}{lrrrr}
\hline & Estimate & Std. Error & $z$ value & $p$ \\
\hline (Intercept) & 3.898 & 0.963 & 4.049 & 0.000 \\
Log(Distance) & -1.222 & 0.157 & -7.798 & 0.000 \\
FFDI & -0.072 & 0.031 & -2.339 & 0.019 \\
Wind_dir: N & -0.591 & 0.506 & -1.167 & 0.243 \\
Wind_dir: S & 0.541 & 0.465 & 1.163 & 0.245 \\
Wind_dir: W & 0.649 & 0.398 & 1.632 & 0.103 \\
Subregion: NW & 0.902 & 0.404 & 2.233 & 0.026 \\
Subregion: SE & -0.592 & 0.402 & -1.473 & 0.141 \\
Subregion: SW & 1.084 & 0.538 & 2.016 & 0.044 \\
SLRV & 7.689 & 1.380 & 5.570 & 0.000 \\
Log(Distance) $\cdot$ FFDI & 0.016 & 0.005 & 3.426 & 0.001 \\
\hline
\end{tabular}

way interactions among all of the variables except the SLRV were tested. The analysis was performed twice, with raw and with log-transformed distance values and the version with the highest explanatory power was selected for the final model. As a further exploration of the role of spatial autocorrelation, the best model with the SLRV was compared to the best model without it and the extent of autocorrelation in the response variable (burnt or not burnt), and in the residuals from 
Table 3. Results of the Kolmogorov-Smirnov tests for difference in distance distributions. The value is the $D$ statistic: the maximum difference in the $y$ axis between lines displayed in Fig. 5. All comparisons were significant at $p<0.001$, except Wildfires vs. Control $(p=0.002)$.

\begin{tabular}{lcccc}
\hline & Control & Roads & Prescribed Fires & Wildfires \\
\hline Roads & 0.481 & & & \\
Prescribed Fires & 0.418 & 0.197 & & \\
Wildfires & 0.183 & 0.486 & 0.380 & \\
High Risk Fires & 0.596 & 0.567 & 0.553 & 0.562 \\
\hline
\end{tabular}

the best model with and without the SLRV were calculated using Moran's I (Haining, 2003).

The cumulative distance distribution data for each set of features (wildfires, high risk fires, prescribed fires, roads and the control set) were compared graphically and Kolmogorov-Smirnov tests were used to determine which features were significantly closer to the buffer than others via two-way comparisons of all combinations.

Hennessy et al. (2005) predicted future weather for southeastern Australia under climate change, and produced a data set of actual and predicted future FFDI data for several weather stations using historical data. We used the data from two weather stations within the study area (Sydney Airport and Williamstown) to estimate the degree of change in the most altered scenario (IPCC 2001 A2 Scenario at 2050 timeline). We found that the predictions of daily FFDI are well described by a linear model of changed versus current FFDI with a coefficient (slope) of 1.108 for Sydney $\left(r^{2}=0.989\right)$ and 1.127 for Williamstown $\left(r^{2}=0.992\right)$. A linear relationship was a better fit than a logarithmic or quadratic relationship. We used the mean of the two coefficients to calculate an adjusted FFDI for each of the fires in the database (i.e. an $11 \%$ increase on current FFDI values). These adjusted FFDI values were substituted for the observed values under current climate in the equation of the best model for burning the WUI buffer, and the predicted probabilities were used to calculate the distance travelled and the likelihood that they would reach the WUI buffer under projections of climate change.

\section{Results}

For the sample of 999 fires, the median distance from the ignition point to the WUI buffer was $2.5 \mathrm{~km}$, though almost $30 \%$ were closer than $1 \mathrm{~km}$ and $8 \%$ were further than $20 \mathrm{~km}$ (Fig. 2a). The majority of fires ignited on days with an FFDI below 12, but the maximum recorded FFDI was 88 (Fig. 2b). A small proportion of the fires $(9.1 \%)$ spread to burn the WUI buffer. The percentage of fires that reached the WUI buffer decreased with the distance of the ignition point from the WUI buffer: i.e. $44 \%$ at ignition distance $<250 \mathrm{~m}$ to $3 \%$ at ignition distance $>3 \mathrm{~km}$ (Fig. 3). The percentage of fires that reached the WUI buffer also increased
Table 4. Proportions of fires reaching the WUI buffer under different weather conditions for current and projected future climates. The column Modelled Current Climate refers to the predicted values from the preferred model and the Modelled Future Climate column used the same model, but with increased FFDI values based on the future climate projection.

\begin{tabular}{lcccc}
\hline \multicolumn{4}{c}{ Proportion Reaching WUI Buffer } \\
\hline Current FFDI & Actual & $\begin{array}{c}\text { Modelled } \\
\text { Current Climate }\end{array}$ & $\begin{array}{c}\text { Modelled } \\
\text { Future Climate }\end{array}$ & \% Increase \\
\hline All data & 0.0891 & 0.0949 & 0.1009 & 6.32 \\
$\leqq 5$ & 0.0566 & 0.0700 & 0.0702 & 0.29 \\
$>5 \leqq 12$ & 0.0599 & 0.0708 & 0.0717 & 1.27 \\
$>12 \leqq 25$ & 0.0878 & 0.0944 & 0.0977 & 3.50 \\
$>25 \leqq 50$ & 0.1391 & 0.0993 & 0.1133 & 14.10 \\
$>50$ & 0.2456 & 0.3129 & 0.3593 & 14.83 \\
\hline
\end{tabular}

with FFDI, such that at ignition distances $>3 \mathrm{~km}$, the percentage of fires reaching the WUI buffer increased from zero at FFDI $<5$ to $12 \%$ at FFDI $>25$ (Fig. 3). Similar trends with FFDI were observed at all distance classes. Westerly winds were more common than winds from other directions (Fig. 2c) and fires were almost twice as likely to spread to the WUI buffer under westerly winds than northerly or easterly, and southerly winds were intermediate (percentages burnt: $\mathrm{N}=4.4, \mathrm{E}=5.8, \mathrm{~S}=10.2, \mathrm{~W}=12.9$ ). Fires were more common in the northwest and northeast subregions than in the southeast or southwest (Fig. 2d) and were much more likely to reach the WUI buffer if they originated in the northeast subregion than in the other subregions (percentages burnt: $\mathrm{NE}=14.8, \mathrm{NW}=4.5, \mathrm{SE}=7.9, \mathrm{SW}=6.1)$.

The best model for the probability of burning the urban buffer contained Ln(distance), FFDI, wind direction, subregion, the SLRV and the interaction between distance and FFDI (Table 2). There were no alternative supported models. The model captured $35.8 \%$ of null deviance. The model predicted that the probability of the WUI buffer burning reduces very rapidly with distance (Fig. 4). When FFDI $\leqq 25$, the probability falls almost to zero at distances above $2 \mathrm{~km}$ (Fig. 4a). When FFDI is 50, the probability falls much more slowly, and remains at about 0.2 even at distances exceeding $10 \mathrm{~km}$. When FFDI $=75$, the probability remains at high at all distances. The wind direction effect in the model reflected the raw data: westerly winds resulted in approximately twice the probability of burning the WUI buffer than easterly or northerly winds across all distances and FFDI levels (Fig. 4b). Among the subregions, the northwest and southwest regions had higher likelihoods of fires reaching the WUI buffer, and the southeast had lower (compared to the northeast) (Fig. 4c). Neither subregion nor wind direction showed an interaction with FFDI or distance. The northeast subregion had the highest likelihood of reaching the WUI ( $14.8 \%$ cf. $4.5 \%$ for NW, $7.8 \%$ for SE and $6.3 \%$ for SW), but this was because ignitions tended to be closer than for other regions (mean distance $1870 \mathrm{~m}$, cf. $11300 \mathrm{~m}$ for NW, 

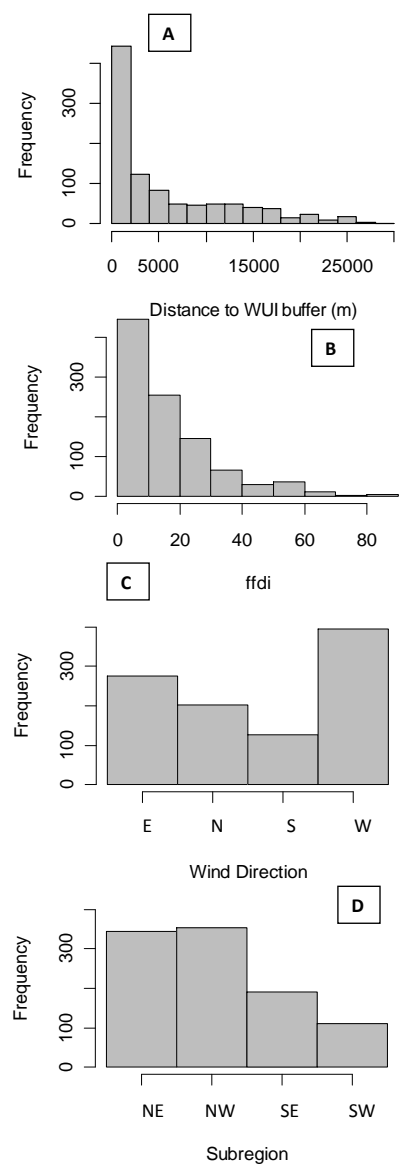

Fig. 2. Frequency histograms for the predictor variables: (A) distance to WUI buffer; (B) FFDI; (C) wind direction; (D) subregion.

$1880 \mathrm{~m}$ for SE and $8120 \mathrm{~m}$ for SW). When distance and weather were controlled for, this region was at relatively low risk (Table 2).

When the SLRV was excluded, the analysis still selected all of the other terms from the SRLV-included model and their coefficients and $p$ values were almost unchanged (for example, the distance estimate changed from -1.222 to -1.246 , and the FFDI estimate from -0.072 to -0.074 ). This model captured $30.7 \%$ of the null deviance. Moran's $I$ test revealed strong spatial autocorrelation in the raw burnt values $(I=0.481, z=4.551, p<0.000)$, and the residuals from the best model without the SLRV. However the residuals from the model with the SLRV were not spatially autocorrelated $(I=-0.112, z=1.05, p=0.29)$.

The distribution of locations of ignition points of wildfires, prescribed fires and roads was closer to the WUI buffer compared with the control sample. Prescribed fires and roads were located closer to the WUI buffer than wildfires, but high risk fires (FFDI $>50$ that burnt the WUI buffer) were the closest of all (Fig. 5, Table 3). While only $20 \%$ of the control points were within $2 \mathrm{~km}$ of the WUI buffer, $44 \%$ of wildfires, $59 \%$ of prescribed fires and $79 \%$ of high risk

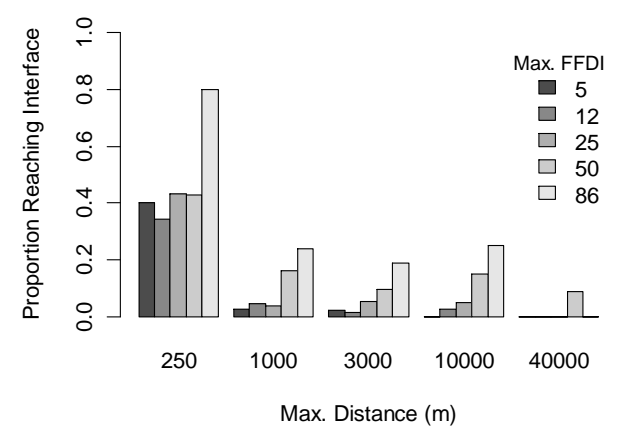

Fig. 3. The proportion of fires that burnt the WUI buffer in different distance and FFDI classes.

fires were within this distance. These differences in distances were confirmed by the two-way Kolmogorov-Smirnov tests, which indicated that all fire types were closer to the WUI buffer than the control sample (significant at $p<0.01$ ).

Under a projected future climate (i.e. Hennessy et al., 2005), a higher proportion of fires were predicted to reach the WUI buffer (Table 4). However, the change was small (6.3\% increase overall), and increased as a function of the FFDI value in the original data. For current FFDI days below 5 , the model predicted a $0.29 \%$ increase in the future likelihood that a fire would reach the WUI buffer, whereas when current FFDI was above 50, then the increase was $14.8 \%$.

\section{Discussion}

The likelihood that a fire will reach the WUI decreases with distance, but this relationship is strongly conditioned by weather so that in extreme weather all fires pose a risk to the WUI, irrespective of how far away the ignition is. To reinforce this unfortunate reality, one of the fires that killed many people in Victoria in 2009 spread more than $40 \mathrm{~km}$ in six hours (Teague et al., 2010).

The WUI is a focus for fire activity and management in the Sydney region. The road network and prescribed fires are concentrated there, but so are wildfires in general and fires that burn the WUI in particular. Comparing the distance distributions of these elements, the focus of management is reasonably well aligned with the risk (i.e. they are slightly biased toward the WUI compared to ignition locations of wildfires in general). However, when we consider that the great majority of high risk fires started within $2 \mathrm{~km}$ of the WUI, it may be argued that an even greater concentration of management near the interface is warranted. When compared to the western USA where only $11 \%$ of treatments were within $2.5 \mathrm{~km}$ of the WUI (Schoennagel et al., 2009), prescribed fires as a fuel reduction treatment are well targeted in Sydney $(59 \%$ within $2 \mathrm{~km})$.

Fire managers have a heuristic understanding of the nature of fire spread, but the quantification allows the effects of 

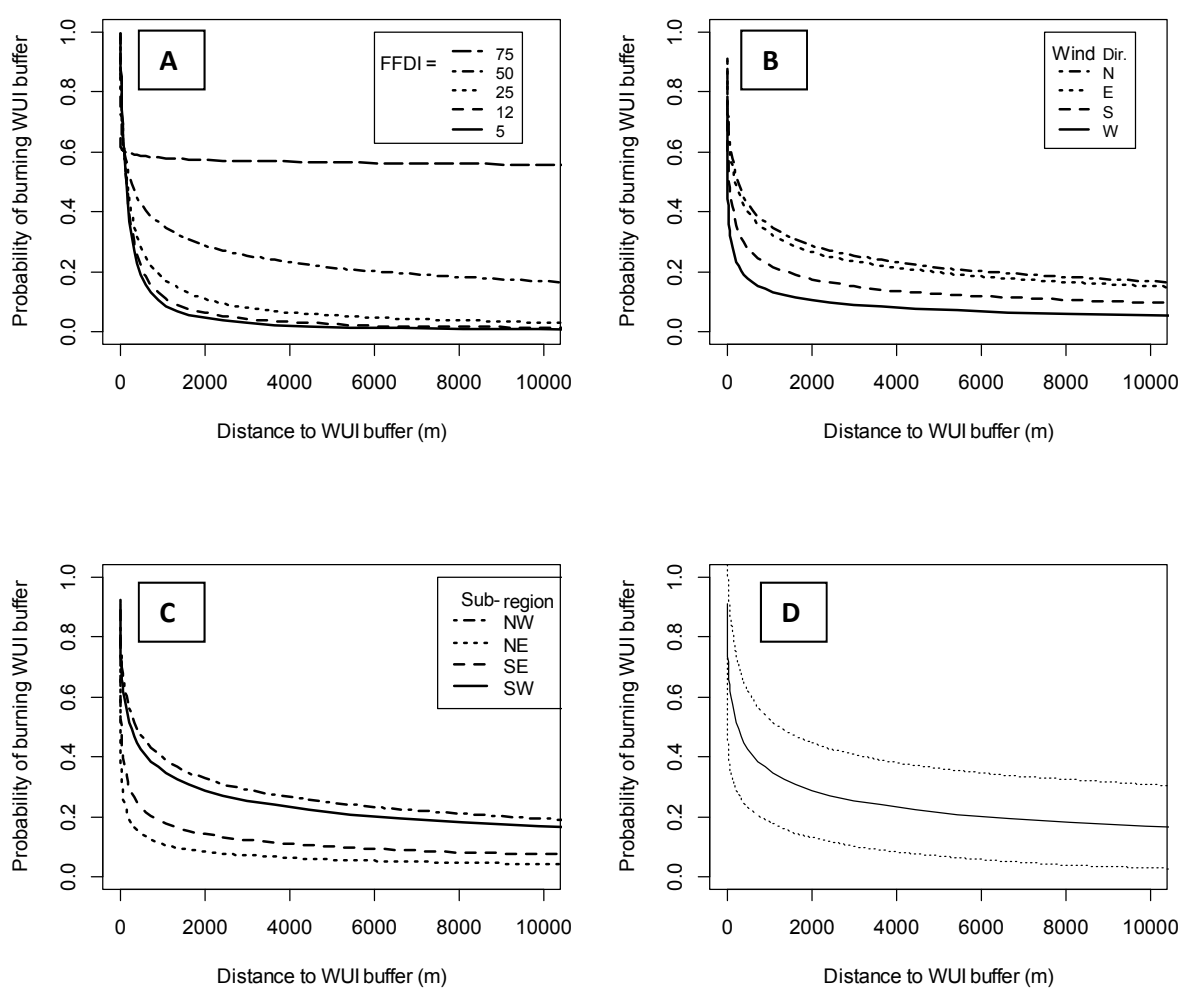

Fig. 4. Model predictions for the probability of burning the WUI buffer: (A) for different FFDI values, with west wind direction and northwest subregion; (B) for each wind direction, with FFDI = 50 and northwest subregion; (C) for each subregion with FFDI = 50 and wind direction = west; (D) Mean (solid) and $95 \%$ confidence interval (dotted) for FFDI = 50, west wind direction and northwest subregion.

weather and ignition location to be partitioned. For example, the likelihood of an ignition $400 \mathrm{~m}$ away burning the buffer under an FFDI of 5 is the same as one $1 \mathrm{~km}$ under an FFDI of 25 , and one $10 \mathrm{~km}$ away under an FFDI of 50 . The results also provide a formal basis for evaluation of the management activities (i.e. roads, fuel treatment) in relation to ignition and the chance of fires spreading to the urban interface. This will be an important ingredient for future cost-benefit analyses of fire management strategies. It should be noted that the risk of reaching the buffer does not encapsulate the full risk to assets, because fires originating further away tend to burn larger areas of the buffer than those with closer origins. In our data, for fires that did burn the buffer, those from $>2 \mathrm{~km}$ away burned almost three times the area of buffer than those from $<2 \mathrm{~km}$ away (mean 308 ha vs. $107 \mathrm{ha}$ ) and there was a significant positive relationship between distance and area of buffer burnt (deviance 164.3, $n=89, p<0.0001$ ).

To date, there have been few attempts to conduct costbenefit analyses that compare different prevention and suppression options (Penman et al., 2011). Ideally, an adaptive management framework would be used to measure how these risks respond to different management strategies. However, in the short term, this study could be used to calibrate fire simulations models, which are then used to conduct "experiments" exploring the effects of different levels of suppres- sion effort, prescribed burning treatments or other strategies on the risk of fires burning the interface. Simulation models have been used in this way (Finney et al., 2007; Stockmann et al., 2010), but the applications usually lack an empirical calibration. Most of the current tools for predicting fire behaviour use mathematical models developed under a limited range of experimental conditions and have not been thoroughly validated against wildfires (Sullivan, 2009). As such they give an imperfect prediction of risk. In contrast, this study quantifies the likelihood of spread based on a large number of real wildfires, including some very large ones (the largest was 87000 ha).

In Sydney, fires were more likely to burn the interface if the wind was westerly. This is presumably because large fires burn predominantly from west to east (as suggested by Cunningham, 1984), which is a consequence of typical synoptic patterns over southeastern Australia in summer (Foley, 1947). It is interesting that this effect is apparent in the models even in the presence of FFDI, which captures wind-speed effects. This probably reflects the inability of FFDI to capture the entire weather effect. Alternatively, it could be because there is more forested land to the west of the WUI in Sydney compared to the east. The eastern regions are more urbanised and therefore protected by urban land and are bounded to the east by the sea (so fewer fires originate there). Fires are also 


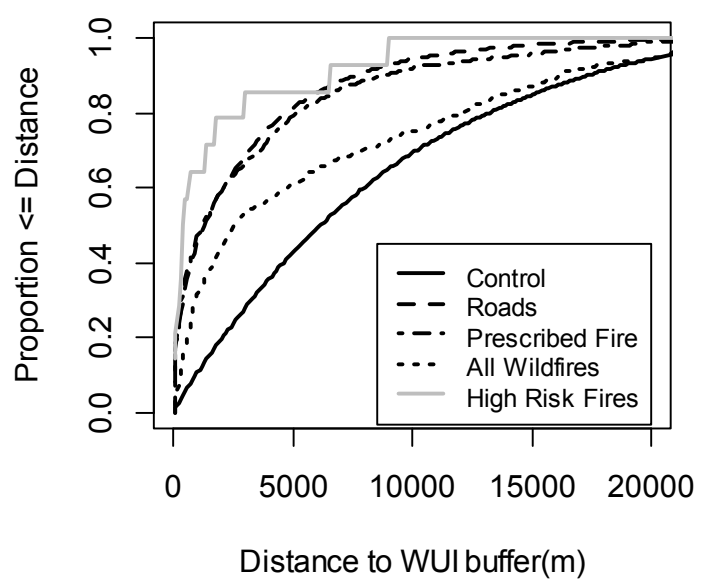

Fig. 5. The cumulative distribution of distance to the WUI buffer for a series of features: random landscape points; roads; prescribed fires; wildfires and wildfires that burnt the WUI buffer on days with FFDI $\geqq 0$ (High Risk Fires). The $y$ axis is the proportion of each feature type that is $\leqq$ to the defined distance on the $x$ axis.

more likely to burn the interface in the southwest and northwest, with approximately twice the likelihood of the other subregions. As with wind direction, this may reflect the tendency of westerly winds to bring worse fires or the relative exposure to forest. There was no interaction between either subregion or wind direction with FFDI or distance, which means the differences among subregions and wind directions are consistent for all weather conditions and distances.

The study provides an empirical basis for assessing how risk may change under future conditions (e.g. climate change). The predicted increase under climate change in likelihood of spread to the WUI was very small under low danger fire weather, but considerable under extreme fire weather. A $15 \%$ increase over a current likelihood of $31 \%$ for FFDI $>50$ represents a risk that fire management agencies should be making contingency plans for. This prediction is in broad agreement with climate change predictions for other fire attributes. For example, Bradstock et al. (2012) found a $30 \%$ increase in simulated annual burnt area by 2050 in the same region and using the same projections of future changes in FFDI as the current study. However, across the world, predictions of the response of wildfire to climate change are highly variable (Flannigan et al., 2009).

As a quantification of the base-rate of fire risk, this study has some shortcomings. Suppression activity was carried out on many of these fires, which probably affected their chances of reaching the WUI buffer. We partially controlled for this by using a buffer $500 \mathrm{~m}$ away from the actual urban edge because much of the suppression effort is concentrated between here and the edge which is where the assets are located. Nevertheless, it is likely that some of the fires that had the potential to burn the buffer were prevented from doing so. This may be particularly true for fires on low FFDI days, because these fires can quickly be controlled and remain small. Thus, we have estimated the risk of spread under the average suppression regime operating between 1977 and 2008, and may have underestimated the risk from fires on low FFDI days if there were no suppression. In order to burn from the ignition point to the WUI buffer, each of the fires in this study had to cross a different combination of vegetation types, recently burnt patches (reduced fuel loads) and disruptions such as roads and rivers. These would all have affected the likelihood of reaching the interface but none of these factors were captured here. This is presumably one of the main reasons why the model did not explain a greater proportion of variation. Investigation of these factors is the subject of our current research, but we believe their exclusion from this study did not bias the quantified relationships because we used a large sample which would have included a representative range of values for each of these factors.

It is unlikely that the distance-risk relationship is the same in all parts of the interface due the differences in the shape and configuration of the interface itself. We have demonstrated that it varies at the subregional scale and that wind direction is one of the modifiers of risk. Thus, areas of the WUI that face east should be at lower risk. But there are additional factors that might be important. For example, the total risk at any place on the WUI is presumably related to the arc of exposure to flammable vegetation. An isolated development surrounded by vegetation on all sides will be at more risk than one which is mostly surrounded by urban land with a narrow arc of flammable vegetation. This effect could be explored by conducting an interface-centric analysis of fire spread, rather than the fire-centric analysis in this study.

\section{Conclusions}

The likelihood that a fire will reach the WUI is the result of an interaction between weather and distance, such that under mild conditions, fires have very low risk if they ignite $>2.5 \mathrm{~km}$ from the interface but under extreme weather conditions, the risk is relatively high and largely independent from distance. The results of this study should be of use to fire management agencies for a number of reasons. Primarily, they provide an evidentiary basis for demarking fire management zones and for tailoring the response to fires to their predicted risk. Secondarily, they may be used as input to a costbenefit analysis aimed at measuring the effectiveness of fire risk reduction strategies. The study has implications beyond the Sydney study region. The fuel types and fire weather in Sydney are generally similar across eastern Australia, and therefore the relationships here could be used to predict fire risk more widely. Internationally, the fuel types and weather associated with fires differ, but the general influence of fuel and weather is similar to Australia. Therefore, our approach could be used to examine the way the chance of ignition and 
spread of fires ultimately determines the probability of loss of property.

Acknowledgements. This study was funded by the Rural Fire Service of New South Wales. We would like to thank the NSW Office of Environment and Heritage for mapping information and assistance in locating ignition points.

Edited by: B. D. Malamud

Reviewed by: D. Calkin and one anonymous referee

\section{References}

Anonymous: Bush fire risk management plan, Blue Mountains Bush Fire Management Committee, Blue Mountains, 97, 2008.

Bar Massada, A., Radeloff, V. C., Stewart, S. I., and Hawbaker, T. J.: Wildfire risk in the wildland-urban interface: A simulation study in northwestern Wisconsin, For. Ecol. Manag., 258, 1990-1999, doi:10.1016/j.foreco.2009.07.051, 2009.

Bhandary, U. and Muller, B.: Land use planning and wildfire risk mitigation: an analysis of wildfire-burned subdivisions using high-resolution remote sensing imagery and GIS data, J. Environ. Plan. Manage., 52, 939-955, doi:10.1080/09640560903181147, 2009.

Blanchi, R., Lucas, C., Leonard, J., and Finkele, K.: Meteorological conditions and wildfire-related house loss in Australia, Int. J. Wildland Fire, 19, 914-926, doi:10.1071/wf08175, 2010.

Bradstock, R. A. and Gill, A. M.: Living with fire and biodiversity at the urban edge: in search of a sustainable solution to the human protection problem in southern Australia., J. Mediterran. Ecol., 2, 179-195, 2001.

Bradstock, R. A., Gill, A. M., Kenny, B. J., and Scott, J.: Bushfire risk at the urban interface estimated from historical weather records: consequences for the use of prescribed fire in the Sydney region of south-eastern Australia, J. Environ. Manag., 52, 259-271, 1998.

Bradstock, R. A., Cohn, J., Gill, A. M., Bedward, M., and Lucas, C.: Prediction of the probability of large fires in the Sydney region of south-eastern Australia using components of fire weather, Int. J. Wildland Fire, 18, 932-943, 2009.

Bradstock, R. A., Cary, G. J., Davies, I., Lindenmayer, D. B., Price, O., and Williams, R. J.: Wildfires, fuel treatment and risk mitigation in Australian eucalypt forests: insights from landscape-scale simulation., J. Environ. Manag., 105, 66-75, 2012.

Brillinger, D. R., Autrey, B. S., and Cattaneo, M. D.: Probabilistic risk modeling at the wildland urban interface: the 2003 Cedar Fire, Environmetrics, 20, 607-620, doi:10.1002/env.959, 2009.

Burnham, K. P. and Anderson, D. R.: Model selection and multimodel inference: A practical information-theoretic approach., 2nd Edn., Springer-Verlag, New York, 353 pp., 2002.

Cunningham, C. J.: Recurring natural fire hazards - a case-study of the Blue Mountains, New-South-Wales, Australia, Appl. Geogr., 4, 5-27, 1984.

Ellis, S., Kanowski, P., and Whelan, R.: National inquiry on bushfire mitigation and management, Council of Australian Governments (COAG), Canberra, 415, 2004.

Finney, M. A., Selia, R. C., McHugh, C. W., Ager, A. A., Bahro, B., and Agee, J. K.: Simulation of long-term landscape-level fuel treatment effects on large wildfires, Int. J. Wildland Fire, 16, 712-727, 2007.

Flannigan, M. D., Krawchuk, M. A., de Groot, W. J., Wotton, B. M., and Gowman, L. M.: Implications of changing climate for global wildland fire, Int. J. Wildland Fire, 18, 483-507, doi:10.1071/wf08187, 2009.

Foley, J. C.: A study of meteorological conditions associated with bush and grass fires and fire protection strategy in Australia, Australian Bureau of Meteorology, Melbourne, 1947.

Haight, R. G., Cleland, D. T., Hammer, R. B., Radeloff, V. C., and Rupp, T. S.: Assessing fire risk in the wildland-urban interface, J. Forestry, 102, 41-48, 2004.

Haining, R.: Spatial Data Analysis, Cambridge University Press, Cambridge, 432 pp., 2003.

Hennessy, K., Lucas, C., Nicholls, N., Bathols, J., Suppiah, R., and Ricketts, J.: Climate change impacts on fire-weather in southeast Australia, CSIRO Marine and Atmospheric Research, Aspendale, Victoria, 2005.

Hughes, R. and Mercer, D.: Planning to Reduce Risk: The Wildfire Management Overlay in Victoria, Australia, Geograph. Res., 47, 124-141, doi:10.1111/j.1745-5871.2008.00556.x, 2009.

McArthur, A. G.: Fire behaviour in eucalypt forests, Forestry and Timber Bureau, Canberra, 36, 1967.

McCullagh, P. and Nelder, J. A.: Generalised linear models, Monographs on Statistics and Applied Probability, edited by: Cox, D. R. and Hinkley, D. V., Chapman and Hall, London, 261 pp., 1983.

Mell, W. E., Manzello, S. L., Maranghides, A., Butry, D., and Rehm, R. G.: The wildland-urban interface fire problem - current approaches and research needs, Int. J. Wildland Fire, 19, 238-251, doi:10.1071/wf07131, 2010

Penman, T. D., Price, O., and Bradstock, R. A.: Bayes Nets as a method for analysing return for investment in fire management planning, Int. J. Wildland Fire, 20, 909-920, 2011.

Price, O. F. and Bradstock, R.: The effect of fuel age on the spread of fire in sclerophyll forest in the Sydney region of Australia, Int. J. Wildland Fire, 19, 35-45, 2010.

Price, O. F. and Bradstock, R.: The influence of weather and fuel management on the annual extent of unplanned fires in the Sydney region of Australia, Int. J. Wildland Fire, 20, 142-151, 2011.

Safford, H. D., Schmidt, D. A., and Carlson, C. H.: Effects of fuel treatments on fire severity in an area of wildland-urban interface, Angora Fire, Lake Tahoe Basin, California, For. Ecol. Manag., 258, 773-787, 2009.

Schoennagel, T., Nelson, C. R., Theobald, D. M., Carnwath, G. C., and Chapman, T. B.: Implementation of National Fire Plan treatments near the wildland-urban interface in the western United States, Proc. Natl. Acad. Sci. USA, 106, 10706-10711, doi:10.1073/pnas.0900991106, 2009.

Stockmann, K., Burchfield, J., Calkin, D., and Venn, T.: Guiding preventative wildland fire mitigation policy and decisions with an economic modeling system, For. Policy Econ., 12, 147-154, doi:10.1016/j.forpol.2009.09.009, 2010.

Sullivan, A. L.: Wildland surface fire spread modelling, 1990-2007, 2: Empirical and quasi-empirical models, Int. J. Wildland Fire, 18, 368-386, 2009.

Teague, B., Mcleod, R., and Pascoe, S.: 2009 Victorian bushfires Royal Commission final report, Parliament of Victoria, Melbourne, 2010. 